\title{
Stress-Strain Behavior of Nylon-Carbon Composite Subjected to High Strain Rate Impact Loading
}

\author{
Noori Hassoon Mohammed Al-Saadi \\ Department of Civil Engineering, Dijlah University College, Baghdad, Iraq
}

Received: June 24, 2015 / Accepted: August 03, 2015 / Published: September 30, 2015.

\begin{abstract}
The aim of this study is to investigate the dynamic stress-strain relation for the hybrid composite (nylon +carbon). Three groups of specimens are used with different number of carbon layers. The specimens were subjected to high velocity impact with different strain rates. SHPB (split Hopkinson pressure bar) is used in this investigation. The results show that, the stress-strain relation various with the strain rate. The maximum stress and strain are proportion directly with the strain rate. Also, the results revealed that, as the number of carbon layer increased, the maximum strain decreased.
\end{abstract}

Key words: High strain rate, split Hopkinson pressure bar, composite, high strain rate impact.

\section{Introduction}

The split-Hopkinson pressure bar is among the most commonly used experimental techniques for the determination of the dynamic behavior of materials strained at rates of up to around $10^{3} \mathrm{~s}^{-1}$. Polymer matrix composite materials and structures are finding increasing uses in high performance applications. High strain rate loading is one of the possibilities in many of such applications. The mechanical properties of composite materials may be different at high strain rate loading compared with those at quasi-static loading. This necessitated carrying out investigations on how mechanical properties of composites would change with strain rate. The widely used technique for the determination of behavior of composites under high strain rate loading is SHPB (split Hopkinson pressure bar) apparatus. The working of this apparatus is based on one-dimensional wave propagation theory in elastic bars [1].

Various studies were carried out on high strain rate behavior of unidirectional and cross-ply glass

Corresponding author: Noori Hassoon Mohammed Al-Saadi, Dr., assistant professor, research field: applied mechanics. E-mail: noorihasson@gmail.com. composites [2, 3] and woven fabric glass composites [4] under compressive loading. Generally, it was observed that, the compressive strength and modulus increase compared with those at quasi-static loading.

Various studies were also carried out on high strain rate behavior of unidirectional and cross-ply carbon composites [5-7] and woven fabric carbon composites [8] under compressive loading. It was observed that, the compressive strength and modulus increase compared with those at quasi-static loading.

The objective of the present study is to determine the behavior of typical nylon-carbon/epoxy composite under high strain rate compressive loading. Force versus time plots based on strain gage signals obtained from incident bar and transmitter bar are derived and compared.

\section{Theoretical Considerations}

The design of SHPB is based on one-dimensional wave propagation in elastic bars which deals with the motion of particles in longitudinal direction. The one-dimensional system can ideally be considered to be of infinite length and negligible diameter. The analytical relations to calculate strain rate, strain, and stress as a function of time in the specimen in SHPB 
testing are [9]:

$$
\begin{gathered}
\dot{\varepsilon}=\frac{-2 c}{L} \varepsilon_{R}(t) \\
\varepsilon_{S}(t)=\frac{-2 c}{L} \int \varepsilon_{R}(t) \mathrm{d} t \\
\sigma_{A V G}(t)=\frac{A_{b}}{A_{S}} \varepsilon_{T}(t) E
\end{gathered}
$$

where, $c$ is the elastic wave velocity in the bars ( $\left.c=\sqrt{\frac{E}{\rho}}\right), L$ is the specimen gage length, $A_{b}$ is the cross-sectional area of the bars, $A_{S}$ is the cross-sectional area of the specimen, $E$ and $\rho$ are the Young's modulus and density of the bars, $\varepsilon_{R}$ is the reflected strain pulse, $\varepsilon_{T}$ is the transmitted strain pulse and $t$ is the time duration.

\section{Experimental Considerations}

\subsection{SHPB Apparatus}

The compressive SHPB apparatus shown in Fig. 1 was used for the present study [8]. The main parts of the compressive SHPB apparatus are: 1 -the incident bar, 2 - the transmitted bar, 3 - the striker bar, 4-the specimen, 5-strain gages, 6-supports, 7-momentum mass, 8- shooting gun, 9-the screw driver, 10-striker's clamper, 11-the rigid beam.

The diameter of the incident and transmitter bars is $12 \mathrm{~mm}$. When the striker bar impacts the incident bar, an elastic stress pulse is generated and travels along the incident bar. When the pulse reaches the specimen, which is sandwiched between the incident and transmitter bars, part of the pulse is reflected and the remaining part is transmitted through the specimen to the transmitter bar. The strain gages are placed at the centers of incident and transmitter bars, respectively for providing the time-resolved measure of the signals. Strain gage on incident bar measures both the incident and reflected pulses, whereas strain gage on transmitter bar measures the transmitted pulse. The strain gages are installed midway of the incident and transmitter bars to avoid overlapping of the reflected signal with the incident signal and to keep the time taken the same for both the signals to avoid time calculations during measurements of the strain. The specimen then undergoes dynamic elastic-plastic deformation. From the reflected pulse, the strain rate applied and the strain in the specimen are estimated, and the transmitted pulse provides a measure of the stress. The entire strain/deformation history within the specimen can be obtained by taking measurements along the incident and transmitter bars from strain gages with the assistance of amplifier and oscilloscope. From these signals and using one-dimensional wave propagation theory, strain rate versus time, strain versus time, stress versus time and stress versus strain history in the specimen can be determined.

\subsection{Specimens}

Specimen dimension design is one of the most important considerations in SHPB testing. In order to minimize the effects of the longitudinal and lateral

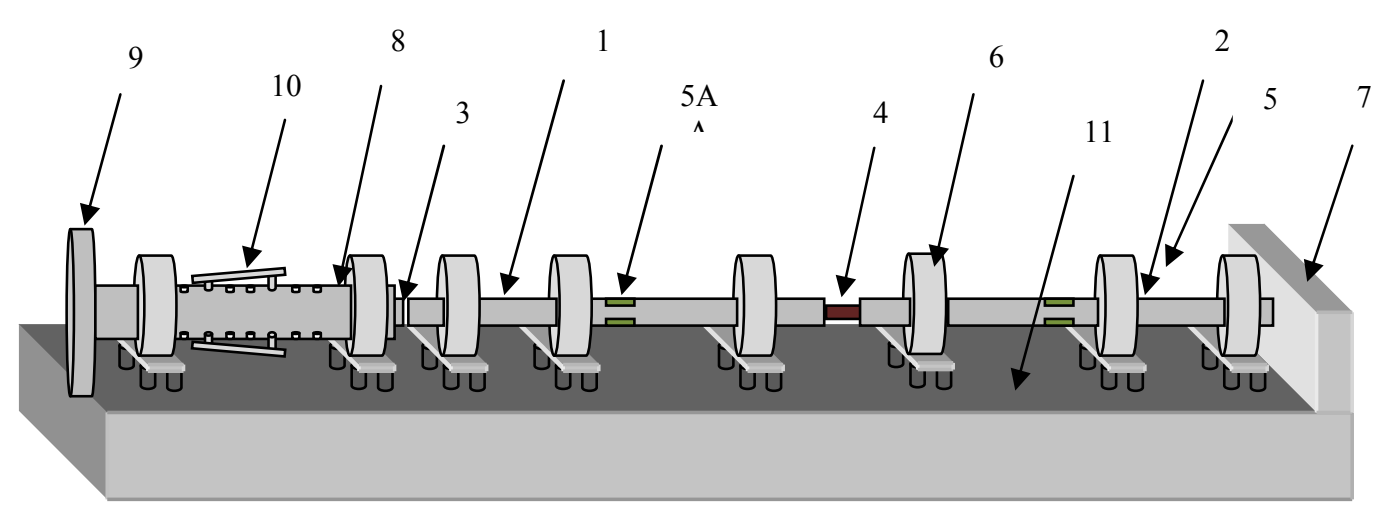

Fig. 1 Schematic of the split Hopkinson pressure bar. 
Table 1 Specimen specifications.

\begin{tabular}{llll}
\hline $\begin{array}{l}\text { Group } \\
\text { number }\end{array}$ & $\begin{array}{l}\text { Lay up } \\
\text { sequence }\end{array}$ & $\begin{array}{l}\text { Number of } \\
\text { layers }\end{array}$ & Lamination layup method \\
\hline A & 313 & 7 & $\begin{array}{l}\text { 3nylon + 1 carbon fiber }+ \\
\text { 3nylon }\end{array}$ \\
B & 323 & 8 & $\begin{array}{l}\text { 3nylon + 2carbon fiber }+ \\
\text { 3nylon } \\
\text { 3nylon + 3carbon fiber }+ \\
\text { C }\end{array}$ \\
\hline
\end{tabular}

inertia and wave dispersion within the specimen, the overall specimen dimensions are required to be small. Previous work in SHPB suggested that, the thickness/diameter ratios of 0.5-2.0 are suitable for cylindrical specimen tests under compression loading [8]. Also the specimens' size must be smaller than the incident and transmitted rods diameters. A cylindrical specimen of $10 \mathrm{~mm}$ diameter was chosen in this work for all types of tested materials. Table 1 shows the groups of the samples.

\section{Results and Discussion}

The dynamic experimental results for three tested groups are shown in Figs. 2-4. It can be seen that, the maximum stress and strain are increased with increasing the strain rate. Also, it can be indicated that, the increasing the number of layers of carbon fibers yielded higher mechanical properties. The results clearly show that, the material response is rate dependent. In general, both the slope of the stress-strain curves and the maximum stress and strain are affected. Figs. 2 and 3 show that, the groups A and B show less rate sensitivity than group $\mathrm{C}$. The strain for the group $\mathrm{C}$ is less than for the other configurations due to increasing the volume fraction of carbon fiber.

Tables 2-4 show that, the strain rate decreasing as the number of carbon layers increasing i.e., the strain increasing with increasing the carbon layers due to increasing the specimen stiffness. Also, the results indicate that, the strain rate is increasing with the impact velocity.

Figs. 5-9 show the variations of stress-strain behavior with the impact velocity. It can be concluded that, the specimen with one layer of carbon has

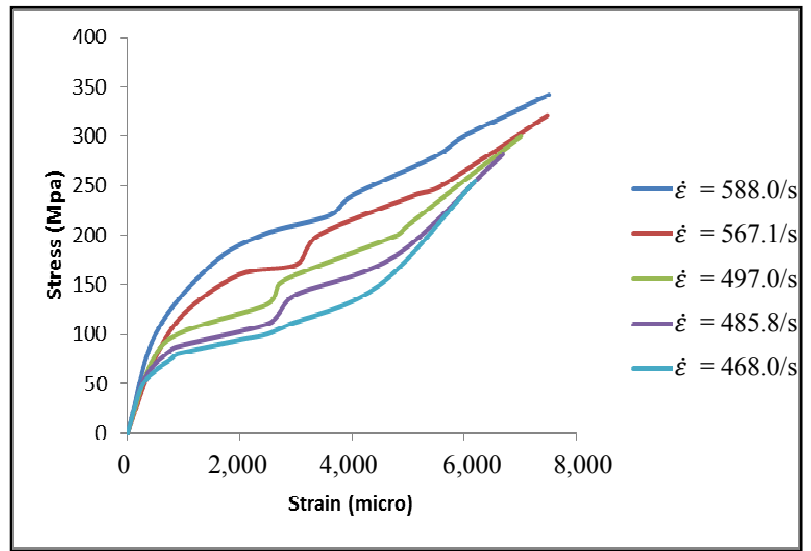

Fig. 2 Dynamic stress-strain curves for (313) lay-up.

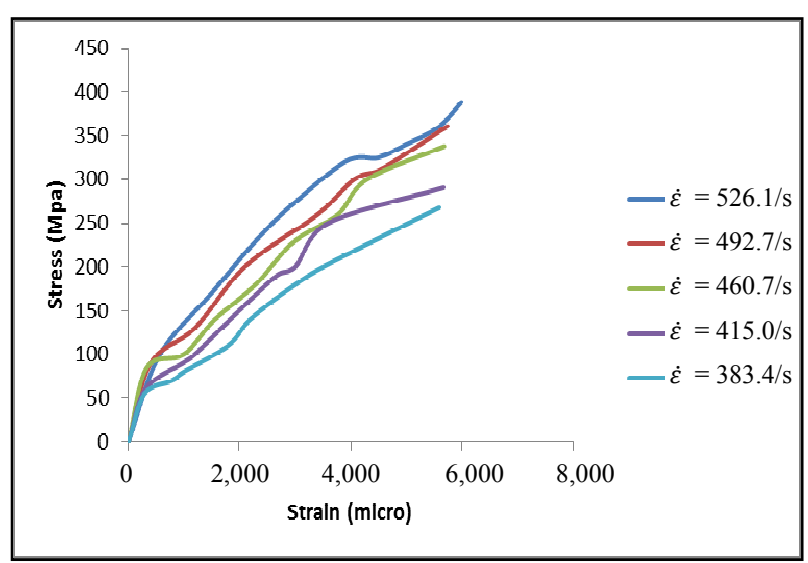

Fig. 3 Dynamic stress-strain curves for (323) lay-up.

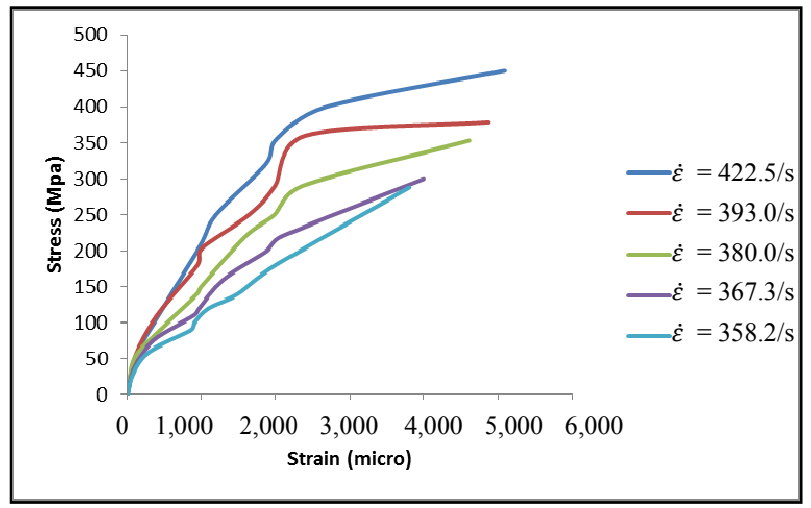

Fig. 4 Dynamic stress-strain curves for (333) lay-up.

Table 2 Maximum stress and strain for (313) lay-up.

\begin{tabular}{llll}
\hline $\begin{array}{l}\text { Group } \\
\text { number }\end{array}$ & Strain rate (1/s) Strain (micro) & $\begin{array}{l}\text { Maximum } \\
\text { stress (MPa) }\end{array}$ \\
\hline \multirow{4}{*}{ A } & 588 & 7,500 & 342 \\
& 567.1 & 7,470 & 321 \\
& 497 & 7,000 & 300 \\
& 485.8 & 6,680 & 282 \\
& 468 & 6,200 & 255 \\
\hline
\end{tabular}


Table 3 Maximum stress and strain for (323) lay-up.

\begin{tabular}{llll}
\hline $\begin{array}{l}\text { Group } \\
\text { number }\end{array}$ & Strain rate (1/s) Strain (micro) & $\begin{array}{l}\text { Maximum } \\
\text { stress (MPa) }\end{array}$ \\
\hline \multirow{4}{*}{ B } & 526.1 & 6,000 & 388.5 \\
& 492.7 & 5,750 & 361.8 \\
& 460.7 & 5,690 & 338 \\
& 415 & 5,678 & 291 \\
& 383.4 & 5,600 & 267.9 \\
\hline
\end{tabular}

Table 4 Maximum stress and strain for (333) lay-up.

\begin{tabular}{llll}
\hline $\begin{array}{l}\text { Group } \\
\text { number }\end{array}$ & Strain rate (1/s) Strain (micro) & $\begin{array}{l}\text { Maximum } \\
\text { stress (MPa) }\end{array}$ \\
\hline \multirow{4}{*}{ C } & 422.5 & 5,089 & 450 \\
& 393 & 4,870 & 378 \\
& 380 & 4,621 & 353 \\
& 367.3 & 4,002 & 300 \\
\hline
\end{tabular}

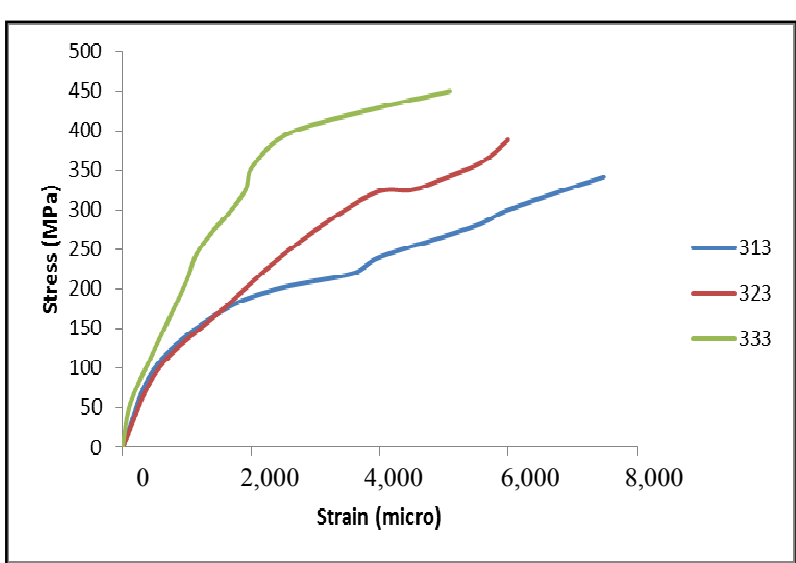

Fig. 5 Effect of number of carbon layer on stress-strain relation $\left(v_{1}=11.3 \mathrm{~m} / \mathrm{s}\right)$.

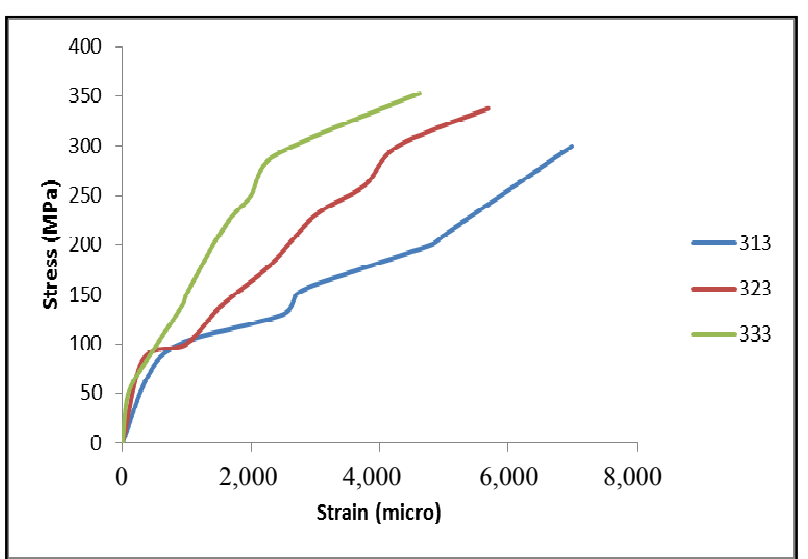

Fig. 6 Effect of number of carbon layer on stress-strain relation $\left(v_{2}=10.45 \mathrm{~m} / \mathrm{s}\right)$.

maximum strain rate for all values of impact velocity. Compared with group A, the strain rate is decreased by
$10 \%, 13 \%, 7 \%, 14 \%$ and $18 \%$ for group B and by $28 \%$, $30 \%, 23 \%, 24 \%$ and $23 \%$ for group C. This is means that, the rate of change in (deformation) of a material with respect to time for group $\mathrm{C}$ is higher than groups $\mathrm{A}$ and $B$.

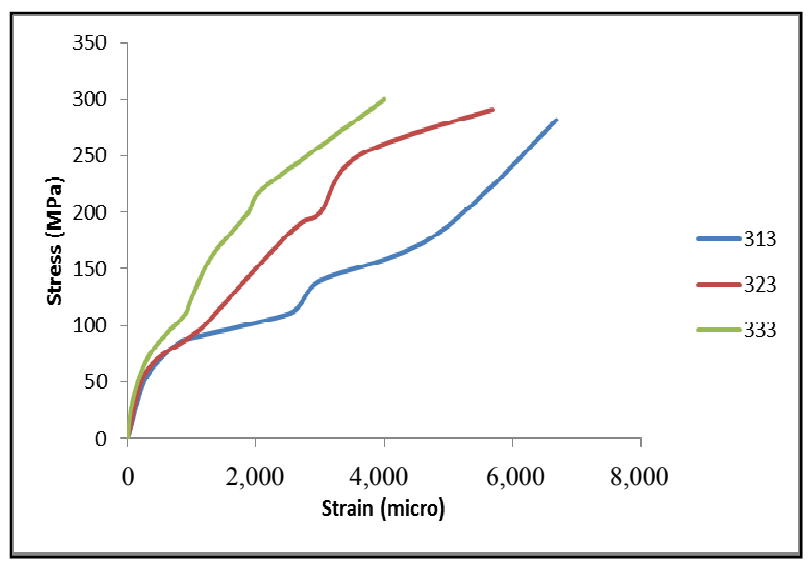

Fig. 7 Effect of number of carbon layer on stress-strain relation $\left(v_{3}=9.62 \mathrm{~m} / \mathrm{s}\right)$.

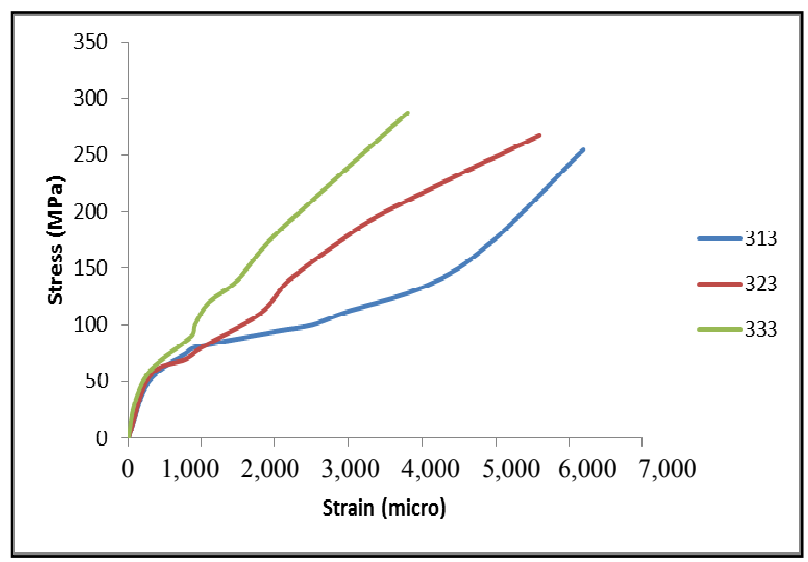

Fig. 8 Effect of number of carbon layer on stress-strain relation $\left(v_{4}=8.78 \mathrm{~m} / \mathrm{s}\right)$.

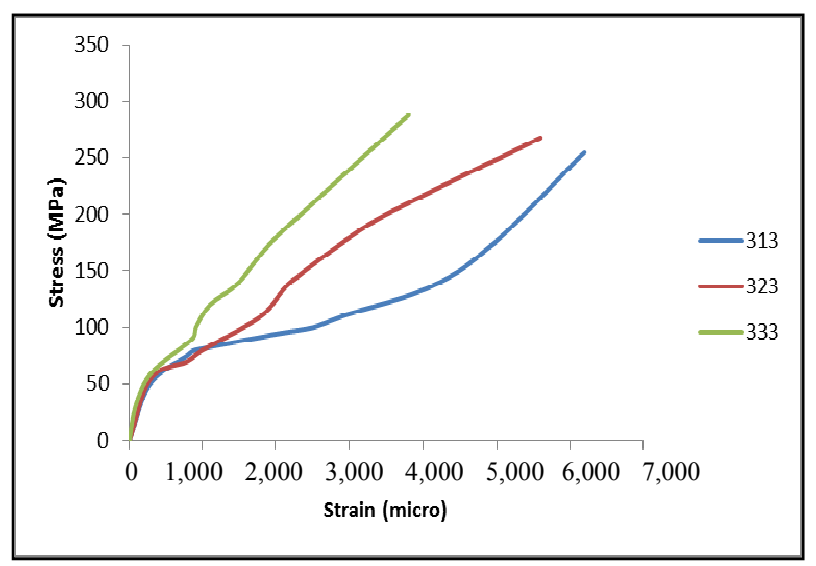

Fig. 9 Effect of number of carbon layer on stress-strain relation $\left(v_{5}=7.11 \mathrm{~m} / \mathrm{s}\right)$. 


\section{Conclusions}

Based on the results were obtained, the compressive strength increases with an increase in strain rates. The maximum stress and minimum strain are observed in the group C (333). On the other hand, the strain rate is increased with the impact velocity while it found the strain rate for the first group A (313) is higher than the other groups at all impact velocities.

\section{References}

[1] Chen, W. W., and Song, B. 2011. "Split Hopkinson (Kolsky) Bar Design, Testing and Applications." In Mechanical Engineering Series. Berlin: Springer Science + Business Media LLC.

[2] Tarfaoui, M. 2011. Experimantal Investigation of Dynamic Compression and Damage Kinetics of Glass/Epoxy Laminated Composites under High Strain Rate Compression. Brest: ENSIETA/MSN. Accessed June 24, 2015. http://www.intechopen.com.

[3] Tsai, J., and Sun, C. T. 2004. "Dynamic Compressive Strengths of Polymeric Composites." International Journal of Solids and Structures 41 (11-12): 3211-21. Accessed June 24, 2015. http://www.elsevier. com/locate/ijsolstr.

[4] Ravikumar, G., Jayram, R. P., Makarand, J., Kiran, A.,
Santosh, K., and Naik, N. K. 2013. "Analytical and Experimental Studies on Mechanical Behavior of Composites under High Strain Rate Compressive Loading." Materials and Design 44 (February): 246-55. Accessed June 24, 2015. http://www.elsevier.com/locate/matdes.

[5] Daniel, I. M., and Hasiao, H. M. 1999. "Effects of Strain Rate and Fiber Waviness on Compressive Behavior of Composite Laminates." In Eng. and Applied Sc. Evanston: Northwestern University, 412-22. Accessed June 24, 2015. http://www.iccm-central.org.

[6] Koerber, H., and Camanho, P. P. 2011. "High Strain Rate Characterization of Unidirectional Carbon-Epoxy IM7-8552 in Longitudinal Compression." Composites Part A 42 (5): 462-70. Accessed June 24, 2015. http://www.elsevier.com/locate/compositesa.

[7] Koerber, H., and Camanho, P. P. 2009. "Characterization of Unidirectional Carbon-Epoxy IM7-8552 in Longitudinal Compression under High Strain Rates." Presented at the 3rd International Conference on Integrity, Reliability and Failure, Porto, Portugal.

[8] Ruaa, A. Y., and Dr. Khaldoon, A. J. 2013. "Investigation of the Effects of Fast Impact on Composite Plates Using Hopkinson Split Bar Method.” Master thesis, University of Al-Mustansiriya.

[9] Jadhav, A. 2003. "High Strain Rate Properties of Polymer Matrix Composites." B.S. Master thesis, University of Pune. 